\title{
The Effect of Reflective Reading on Reading Comprehension of Iranian EFL Learners
}

\author{
Nava Nourdad (Corresponding author) \\ University of Tabriz, Tabriz, Iran \\ E-mail: nourdad@tabrizu.ac.ir \\ Rasoul Asghari \\ E-mail: Rasulasghari2010@yahoo.com
}

\author{
Received: 26-04-2017 \\ Accepted: 15-06-2017 \\ Advance Access Published: September 2017 \\ Published: 01-11-2017 \\ doi:10.7575/aiac.ijalel.v.6n.6p.267 \\ URL: http://dx.doi.org/10.7575/aiac.ijalel.v.6n.6p.267
}

\begin{abstract}
Reading comprehension as a survival skill in EFL context is included in almost all language proficiency and achievement tests. However, it seems that traditional approaches to reading comprehension instruction have not been successful at satisfying the learners' need. Considering the advantages of reflective reading, it appeared as a probable solution to reading problem of EFL learners. Therefore, this experimental study aimed at investigating the effect of reflective reading on reading comprehension of Iranian EFL learners. To this end 49 male and female participants were selected through convenient sampling and were randomly assigned to two control and experimental groups. An English proficiency test was given to the sample to make sure about the homogeneity of the participants and equality of proficiency levels of the two groups. Later reading comprehension ability of the study groups was measured. As the ten-session treatment began the experimental group experienced reflective reading, while the control group followed conventional method of reading and answering comprehension check questions. After the treatment period, the groups' reading comprehension ability was assessed once more. Independent samples t-tests were run to analyze the gathered data. It was found that reflective reading has positive effect on reading comprehension of Iranian EFL learners. Pedagogical implications of this finding for language teachers, learners, material developers, policy makers and researchers are discussed.
\end{abstract}

Keywords: reflective reading strategies, reflective learning, reading reflection, reading comprehension

\section{Introduction}

Reading ability has always been viewed as critical to academic success (Bernhardt, 1991). Reading comprehension has been one of the important skills and maybe the most important one in Iranian EFL context. Almost all English tests include reading comprehension section. Actually, it is the most commonly used skill for gaining knowledge, because English is hardly ever spoken outside the EFL classroom (Davoudi \& Yousefi, 2015). In spite of being the focus of textbooks and conventional teaching methods, reading comprehension of the learners, unfortunately has not reached the acceptable level.

Students usually lack adequate reading skills which results in comprehension deficiencies and lack of reading efficiency (Ahmadpour, Bagherzadeh, \& Valipur, 2014; Rezaei, Rahimi, \& Talepasan, 2012). In EFL settings like Iran the majority of learners tend to focus on word by word reading, sticking at every unknown word. This hinders their comprehension of the author's intended message and limits the focus of readers' attention to word level.

In Iran many students still have problems in reading comprehension (Ahmadpour, Bagherzadeh, \& Valipur, 2014). Possible reasons for problem in reading comprehension can be the teaching method (Boehm \& Gallavan, 2000), lack of grammatical or vocabulary knowledge (Hirsch, 2003; Qian, 2002; Bensoussan, 1990), lack of background knowledge (Dewitz \& Dewitz, 2003), and low motivation to read (Alderson, 2000).

Poor readers usually cannot distinguish effective and poor strategies and their effects on reading comprehension. They are not also well at monitoring activities during reading (NokhbehRousta \& Ghazi Mirsaeed, 2012). Brown and Palincsar (1985) believe an effective reading instruction program needs identifying complementary strategies modeled by the teacher and learnt by the learner believing in their usefulness. As a remedial method for reading comprehension, reflective reading has been suggested recently.

Reflective reading is one of the effective strategies for reading comprehension. Bressoud (2008) has suggested reading reflection for enabling learners to overcome their reading tasks. Through this practice, learners assert their reflections about the reading text after accomplishing each reading task and before attending class. Therefore, learners summarize the main ideas of the reading, and they write about their understanding and feeling about the reading text. It has been mentioned that reflective reading practice motivates learners to read regularly and it also improves understanding of the content and boost learners' development of monitoring, reflection skills, and self-evaluation (Bressoud, 2008). Learners' examination, revision, and evaluation of their beliefs and experiences throughout the texts are highly required in reflective 
reading. So doing, learners evaluate their beliefs and experiences which lead to certain understandings of texts.

Abilities to understand the reading process and making meaning based on the personal contexts are the characteristics of good reading skills (Lew \& Schmidt, 2011). Reflective reading encourages learners to examine the relationship between information and conclusion. Reflective reading shows learners how moving from information to conclusion is often affected by individuals' histories, cultures, beliefs, and experiences which are extra-textual features (Lew \& Schmidt, 2011). Most of the reflective reading strategies includes writing (e.g. journal writing, reporting, think-aloud etc.), and it is another fortifying factor in helping the learners to understand the text better though reflective reading.

Being a newly suggested method, it has not been widely investigated yet. Therefore, this study was designed to investigate whether reflective reading can have any effect on reading comprehension of Iranian EFL learners. To this end the following research question was posed:

\section{R.Q.: Does reflective reading have any effect on the reading comprehension of Iranian EFL learners?}

\section{Review of the Related Literature}

\subsection{Reading Comprehension}

Studies on reading comprehension include the effects of different types of strategies for improving reading comprehension. For example, Sporer, Brunstein, and Kieschke (2009) tried to investigate the effect of three strategy instructions on school students' reading comprehension ability. Experimental groups were taught four reading strategies (summarizing, questioning, clarifying, predicting) and practiced these strategies in small groups (reciprocal teaching), pairs, or strategy-based instructor-guided instruction. The result showed that the experimental groups had higher scores in reading comprehension tests.

In another study, Su (2006) investigated the effect of the teaching strategies on reading skill. The findings showed that the instruction was fruitful. These strategies included guessing vocabulary from context and looking for key words. In favor of strategy, Yeh's study (2006) proved the positive effect of teaching reading strategies on reading comprehension performance and the attitude towards such instruction.

Reviewing studies which applied different strategies in order to deal with reading comprehension shows those effective strategies had positive effect on reading comprehension and there is more room to study the newly suggested strategies and models in order to improve reading comprehension. One of these newly suggested strategies is called reflective reading which is not investigated in Iranian context and there is need to study its effect.

\subsection{Reflective Reading}

Reflective reading is a branch of reflection concept. In Dewey's (1933) reflective reading approach, manipulation of knowledge towards the generation of knowledge is focused. Reflection occurs when learner notes that his/her understanding is different from the reality and then s/he identifies this difference and plans for it (Cowan, 1998, p.16).

One of the reflective reading strategies is Think-Aloud in which the reader can present the internal dialogue about an observable text (Walker, 2005). So doing, teachers observe the learners thinking while reading.

Journal writing is another Reflection reading strategies. In reflection journals, writing helps facilitate reflection. It has been agreed that writing facilitates learning and helps in integration of new knowledge (Crowe \& Youga, 1986). Learners are forced to think in order to clarify and modify their ideas and understanding through journal writing and consequently revise their understanding in a different form. Developing and recognizing the habits of mind associated with problem solving is one of the aims of journal writing (Stephien, Gallagher, \& Workman, 1998, p. 153). Writing makes a learner filter, reconstruct, organize, gather, process, and feel the experiences that s/he has undergone. Teachers believe that students can develop their own understanding about subjects through journal writing process, and construct their own knowledge base.

Wirth and Aziz (2009) evaluated the effect of reading reflections on reading, learning, and self-awareness of students. The learners had reading reflections after each reading task. The reflections encouraged more regular reading and improved content mastery, development of monitoring, self-evaluation, and reflection skills. Reading reflections also facilitated 'justin-time' teaching. The results of the study confirmed that reading reflections in the courses resulted in improvements in reading and course performance. The researchers mention that reading reflections are useful in improving learning. Reading reflections make learners read more regularly before class, read more deeply, and use various strategies. The reflections are even more effective for under-performing learners.

Holmes and Moulton (1997), investigated the perspectives of second-language university students on dialogue journal writing as a strategy for learning English. The learners had dialogue journal entries 15 weeks, and were interviewed at the end. They reported promotion in both writing fluency and motivation. Trites' (2001) study showed that leaners enjoyed sharing their ideas with their teacher and peers, and as a result of journal writing built a closer relationship with them.

Ghaith and Obeid (2004) instructed think-aloud strategies and found an improvement in overall reading. The learners confirmed this finding in the follow-up interview sessions and mentioned that they will use it in future.

The recent attention on reflective learning and the limited number of the studies in the field reflects an absolute need to investigate the issue comprehensively. The importance of such studies is even greater in EFL context of Iran, where learners not only suffer from sever reading comprehension problems, due to lack of the required skills and strategies, but also have no practice on reflection, neither at home nor in educational contexts. Considering these severe problems, the 
present study aimed at investigating the probable effect of reflective reading on enhancing reading comprehension ability of Iranian adult EFL learners

\section{Methodology}

\subsection{Participants}

To have the intended and appropriate participants four pre-intermediate level classes with the total number of 58 learners from the whole number of the existing population in a foreign language institute $(n=342)$ were selected for this study. The sampling method was non-random convenient sampling from the classes of the researchers. The homogenies participants $(n=49)$ were participating in four intact classes. The control group $(n=23)$ and experimental group ( $\mathrm{n}=26)$ were randomly assigned for the study. Both female and male learners with almost equal number were participated in the study. The learners were all Iranian EFL learners with Turkish as their mother tongue and Persian their second and official national language. None of the participants had an experience of staying in an English speaking country.

\subsection{Material}

A language proficiency test of (PET) was used to select a homogeneous sample regarding English language proficiency. Besides, reading comprehension tests were applied to gather information about the participants' reading comprehension performance before and after the treatment. These reading comprehension tests included 20 items. The tests were designed by the researchers and in order to check their reliability and validity, pilot studies were designed prior to the study. The texts were unseen and were adopted from reading sections of parallel EFL text books of pre-intermediate level other than the course books of the participants. The results of pilot studies revealed reliability of .83 and .77 based on Cronbach's alpha for pre-test and post-test reading comprehension tests respectively. The validity of the items was also double checked by an expert EFL teachers.

\subsection{Procedure}

A convenient sample comprising of 58 learners was selected from the population of the study in an English language Institute. The intact classes were given a PET test and 49 homogeneous learners whose scores fell between \pm 1 standard deviation were selected for this study. Furthermore, an independent samples t-test was run to compare the proficiency levels of the two study groups, the results of which did not reveal a statistically significant difference.

In order to compare the study groups' reading comprehension skill, a reading comprehension pre-test was given to the participants and the results showed that the groups did not have any significant differences prior to the treatment.

By the treatment phase, reflective reading model for reading comprehension tasks was administrated to experimental group and conventional techniques for reading comprehension task was administrated to control group. Experimental group was familiarized with dialogue journal writing. Therefore, the learners were told to use a binder or notebook in order to take notes on the left hand page and write their reflections on right hand page. On the left side, the source of the reading, quotations that stand out, a summary of key points, steps or procedures, models or frameworks were included. Some questions were written in order to submit their responses.

Additionally, they were asked to reflect on how the information fits with their current knowledge or experience, ask themselves questions such as "Did I learn something new?", "What was helpful about this reading?". The treatment lasted for ten sessions during which the instructor provided the participants with explicit explanations on the nature of the task, modeled some reflective reading and gave them the chance to go over the new experience each session in the class. They were also asked to use the acquired strategy at home to perform the intended task for the following session. Since the technique was quite new and unknown to the learners some time was specified to answer the readers' probable questions or to solve the related problems which decreased noticeably during the treatment sessions.

By fulfilling the treatment period, the groups were given reading comprehension post-test, the results of which were analyzed applying another independent sample t-test.

\subsection{Design}

The design of the present study was quasi-experimental research. Since there was lack of random selection of the sample, the language proficiency test (PET) was applied among the participants to assure about their homogeneity in language proficiency and select homogeneous sample out of convenient sample. The participants were divided into two groups; an experimental group and a control group. Since the study was to investigate the effect of reflective reading on reading comprehension of Iranian EFL learners, reading ability of the study groups were measured before the treatment and the groups' means and possible differences in variance were compared. The treatment of the study included 10 sessions of reading comprehension classes. After the treatment period, the groups' reading comprehension ability were measured again. By gathering the reading comprehension post test scores the performances of the two study groups in reading comprehension and their motivation rate were compared to get the results of the study.

\section{Findings and discussion}

\subsection{Descriptive Statistics}

Descriptive statistics of reading comprehension tests including mean score and standard deviation of both experimental and control groups are provided in Table 1. 
Table 1. Descriptive Statistics of Reading Comprehension Tests

\begin{tabular}{lllll}
\hline \multirow{3}{*}{ Pre-test } & Control Group & Mean & $\mathrm{N}$ & Std. Deviation \\
\cline { 2 - 5 } & Experimental Group & 7.00 & 23 & 1.34 \\
\hline \multirow{2}{*}{ Post-test } & Control group & 6.69 & 26 & 1.28 \\
\cline { 2 - 5 } & Experimental group & 7.60 & 23 & 1.49 \\
\hline
\end{tabular}

As it is shown in Table 1, the mean score for control group was 7 prior to the treatment and 7.60 in post treatment. The mean score for the reflective reading group was 6.69 prior to the treatment and 8.38 in post treatment. Both groups showed increase in reading comprehension after the treatment. The increase was less than 1 point for control group and slightly less than 2 points for experimental group.

\subsection{Inferential Statistics}

To investigate the possible difference in reading comprehension between two groups of the study prior to the treatment, an independent samples t-test was run, the results of which are presented in Table 2.

Table 2. Independent Samples t-test for Reading Comprehension Pre-test

\begin{tabular}{|c|c|c|c|c|c|c|c|c|c|c|}
\hline & & $\begin{array}{l}\text { Leve } \\
\text { for } \\
\text { of } V\end{array}$ & $\begin{array}{l}\text { e's Te } \\
\text { Equali } \\
\text { iance }\end{array}$ & $\begin{array}{l}\mathrm{y} \text { tt-tes } \\
\mathrm{y}\end{array}$ & or Equ & lity of I & Means & & & \\
\hline & & $\bar{F}$ & Sig. & $\mathrm{t}$ & df & $\begin{array}{l}\text { Sig. } \\
\text { tailed) }\end{array}$ & $\begin{array}{l}\text { (2-Mean } \\
\text { Difference }\end{array}$ & $\begin{array}{l}\text { Std. Error } \\
\text { Difference }\end{array}$ & $\begin{array}{r}95 \% \\
\text { Int } \\
\text { D }\end{array}$ & $\begin{array}{l}\text { fidence } \\
\text { of the } \\
\text { ence }\end{array}$ \\
\hline & & & & & & & & & Lower & Upper \\
\hline Reading & $\begin{array}{l}\text { Equal variance } \\
\text { assumed }\end{array}$ & $\mathrm{s} .17$ & .68 & .81 & 47 & .41 & .30 & .37 & -.45 & 1.06 \\
\hline Scores & $\begin{array}{l}\text { Equal variance } \\
\text { not assumed }\end{array}$ & & & .81 & 45.6 & .42 & .30 & .37 & -.45 & 1.06 \\
\hline
\end{tabular}

According to Table 2, independent samples t-test showed no significant difference between control and experimental groups' reading ability prior to the treatment $(\mathrm{p}=0.41$ (2-tailed), $\mathrm{t}(47)=0.81, \mathrm{p}>0.05)$. So the two study groups were almost the same in reading comprehension prior to the treatment.

In order to answer the research question, does reflective reading have any effect on the reading comprehension of Iranian EFL learners? another independent sample t-test was run. This test was run in order to understand the possible difference between reading comprehensions post-test. The results of this independent sample t-test are shown in Table 3.

Table 3. Independent Samples t-test for Reading Comprehension Post-test

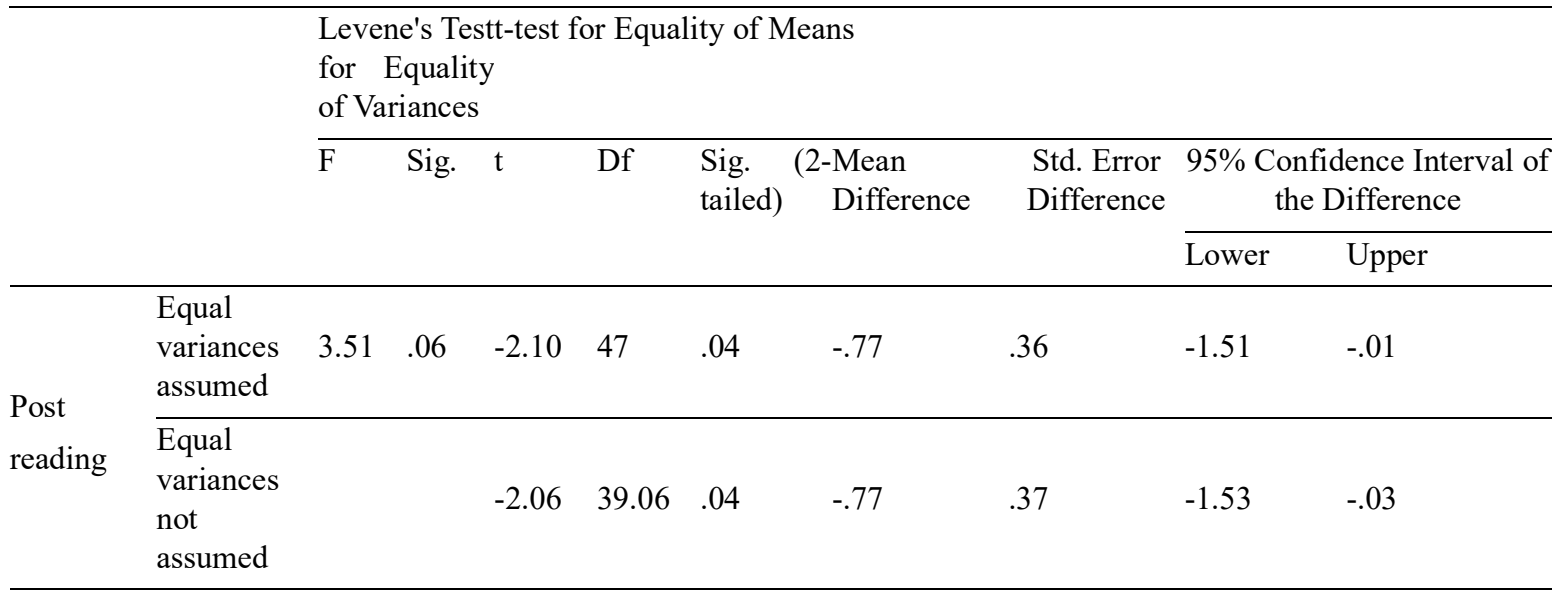

As it is shown in Table 3, the results $(\mathrm{p}=.04$ (2-tailed), $\mathrm{t}(47)=-2.10, \mathrm{p}<0.05)$ indicate a significant difference between the groups' reading comprehension scores after the treatment. Therefore, the experimental group $(M=8.38, S D=1.06)$ had 
higher reading comprehension performance than the control group $(M=7.60, S D=1.49)$ after the treatment. Consequently, reflective reading proved to be influential in increasing reading comprehension performance of Iranian EFL learners.

The present study found the positive effects of reflective reading strategies on reading comprehension performance of Iranian EFL learners. These findings are in line with the findings of previous related studies in the field (Wirth \& Aziz, 2009; Alexander, 2001; Andrusyszyn \& Davie, 1997; Carroll \& Mchawala, 2001; Jonassen, 1994; Trites, 2001).

In line with Wirth and Aziz, the present study showed the positive effect of reflective reading on reading comprehension. Wirth and Aziz (2009) evaluated the impact of reading reflections on student reading, learning, and self-awareness as learners. In their study, students submitted reading reflections after completing each reading assignment. These reflections not only encourage students to read more regularly, they also promote content mastery and foster student development of monitoring, self-evaluation, and reflection skills. As Wirth and Aziz (2009) discussed, reflective reading strategies make the learners more attached to the task, to read repeatedly, to self-evaluate their own performance which yield in better performance in reading comprehension. From the existing literature and methods for comparing with the findings of the present study, there was no study showing the lack of positive effect of reflective reading strategies on reading comprehension.

Reading is directly related to thinking, so instruction on thinking can positively affect reading ability of the learners. As an active decoding process, reading requires a close relationship between reader and text. Comprehension involves extraction of information from text and integrating its various components in the best possible way while connecting them to existing schemata of prior knowledge. This requires high levels of thinking and creativity on the part of reader. Both reflection and creative thinking involve cognitive and metacognitive strategies which are essential for comprehension. Danesh and Nourdad (2017) reported a significant positive relationship between creative problem solving (CPS) skill and reading comprehension. The results of their study revealed that students with higher CPS had better comprehension of the texts. Reflection as a key element in creative thinking and creative problem solving, therefore, can have a relationship with reading comprehension.

Reflection in particular goes well with higher order tasks. To answer higher order thinking questions, memorization of facts and knowledge will not work. Readers attempt to put the gained information in a new perspective by manipulating the text, developing an active link between the pieces, and creating new combinations (Nourdad, 2015). Through reflection the learner may revise his/her understanding from the reading text, which results in self-guidance and independent learning. Through reflection, the learner also gains a network of understanding and at the end of the process $\mathrm{s}$ /he puts all the gathered understanding to make a whole understanding of the material. Reflection helps learners to clarify their thoughts, to gain insights and to understand the received information more deeply (Higgs, 1988, p.47).

Through journal writing, learners write their thoughts and understanding. Writing makes the learning process easier and helps integration of new knowledge. Writing makes learners think, consequently, clarify and modify his/her ideas. The learner needs to revise his/her understanding of the text. This revision is continuously done by reading the upcoming paragraphs and acquiring additional information provided within the text. Therefore, through reflective reading and presenting it in their journal writing, learners build on their understanding of the knowledge linking the new information to the old. The readers, consequently, come up with the very crucial role of the context, and realize the very important role context plays in reading comprehension. So, they try to make a meaningful map between different concepts in the reading comprehension text and make a general comprehension and understanding from the text. This in turn results in putting away the unfruitful practice of reading the text sentence by sentence, translating word by words and missing the intended message of the author.

Since it was concluded that reflective reading strategies were helpful in improving the reading comprehension skill of the learners, the language curriculum developers, syllabus designers, and teachers can use these strategies in their planning, textbooks, and methods to improve the learners' reading comprehension skill. English language teachers can take these strategies for teaching reading in order to improve their learners reading comprehension. Not only at institutes but also at school and university classes, instructors can apply these strategies. Syllabus designers should specify a section of each unit to reflective strategies and questions. Tasks can be developed purposefully to enhance learners' reflective thinking, reflective reading, and accordingly reading comprehension ability. Test developers can also take advantage of positive washback effect of the items included in the test to move learners toward reflection.

The implications of these findings are by no means limited to foreign language teaching and learning. It is also best suited to the educational context in its broader terms. Unfortunately, Iranian education system in all its levels suffers from major drawbacks in theory and practice. Taking a psychological approach to education and considering learners more than individuals for rote memorization of massive data, curriculum developers need to reconsider their definitions of education. The current materials need to undergo revision to move the learners toward self-awareness, control of learning, autonomy, motivation, and reflection. Learners should be reflective practitioners while reflection is defined as a mental process of thinking and learning in everyday life.

Savin-Baden (2000, p. 9) defines learning as a 'cyclical process' in which learners develop understandings of themselves and their contexts and the ways and situations in which they learn effectively. In this constructive perspective learning is gaining in knowledge and understanding the world around through questioning, interpreting, and analyzing information. A learner should be a reflective practitioner and it definitely needs to be considered in educational systems. 


\section{Conclusion}

New studies in reading are showing that one out of five students has significant difficulty in reading acquisition (Hausheer, Hansen, \& Doumas, 2011), so it is important to solve this commonplace problem among the learners. Lower performance not only yield in less score but also it yields in discouragement and demotivation as well. One probable solution for improving reading comprehension is reflective reading strategy. The present study aimed to find out the effect of reflective reading on reading comprehension ability of EFL learners. As the result proved the positive effect of reflective reading strategies on reading comprehension of the learners, it can be concluded that reflection forms the important link between processing the new information and integrating it with the existing understanding of the reading text. Through the reflection the learner may revise his/her understanding from the reading text, which causes to the self-guidance and independent learning. Through different reflection, the learner provides a network of understanding and at the end of the process $\mathrm{s} /$ he puts all learned understanding to make a whole understanding of the material. The value of reflection in learning lies in its ability to help learners to clarify their thoughts, to gain insights and to deepen their understanding of the information that they receive (Higgs, 1988, p.47). Language teachers should push their learners a level above the word by word reading of the texts and teach them the macro level look through reflection. This not only improves their reading comprehension but also moves them toward higher order thinking skills which are the key to academic success.

\section{References}

Ahmadpour, S., Bagherzadeh, M., \& Valipur, V. (2014). The effect of using L1 reading comprehension task on Iranian EFL learners' L2 reading comprehension test score. Asian Journal of Social Sciences \& Humanities, 3(2), 37-43.

Alderson, J. C. (2000). Assessing Reading. Cambridge: Cambridge University Press.

Alexander, N. (2001). A long day's journal into night: A primer on writing dialogue journals with adolescent ESL students. In J.I. Burton \& M. Carroll (Eds.), Journal writing: Case study in TESOL practice series (pp. 23-35). Alexandria, VA: Teachers of English to speakers of Other Languages.

Andrusyszyn, M.A., \& Davie, L. (1997). Facilitating reflection through interactive journal writing in an online graduate course: A qualitative study. Journal of Distance Education, 12(2), 103-126.

Bensoussan, M. (1990). EFL reading as seen through translation and discourse analysis: Narrative vs. Expository texts. English for Specific Purposes, 9, 49-66.

Bernhardt, E. B. (1991). Reading Development in a Second Language: Theoretical, Empirical, and Classroom Perspectives. Norwood, $\mathrm{Nj}$ : Ablex.

Boehm, R. F., \& Gallavan, N. P. (2000). Adapting cooperative learning to an introductory analysis class. Journal of Engineering Education, 89(4), 419-421

Bressoud, D. (2008). Getting students to read. Launchings: Mathematical Association of America. Retrieved on 18 March 2016 from: https://www.maa.org/external_archive/columns/launchings/launchings_5_08.html\#key1

Brown, A. L., \& Palincsar, A. S. (1985). Reciprocal teaching of comprehension strategies: A natural history of one program for enhancing learning. Technical Report No. 334. Cambridge, MA: Illinois

University, Urbana Center for the Study of Reading.

Carroll, M., \& Mchawala, C. (2001). Form or meaning? Academic writing with a personal voice. In J.I. Burton \& M. Carroll (Eds.), Journal writing: Case study in TESOL practice series (pp. 47-58). Illinois: Teachers of English to speakers of Other Languages.

Cowan, J. (1998). On Becoming an Innovative University Teacher: Reflection in Action. UK: The Society for Research into Higher Education and Open University Press.

Crowe, D. \& Youga, J. (1986). Using writing as a tool for learning economics. Journal of Economic Education, 17, 218222.

Danesh, M., \& Nourdad, N. (2017). On the relationship between creative problem solving skill and EFL reading comprehension ability. TPLS, 7(3), 234-240.

Davoudi, M., \& Yousefi, D. (2015). Comprehension breakdown: a review of research on EFL learners' reading difficulty and problems. International Journal of Language and Applied Linguistics, 1, 58-72.

Dewey, J. (1933). How We Think. Boston: D.C. Heath and CO.

Dewitz, P., \& Dewitz, P. K. (2003). They can read the words, but they can't understand: Refining comprehension assessment. The Reading Teacher, 56(5), 422-435.

Ghaith, G. \& Obeid, H. (2004). Effect of think aloud on literal and higher-order reading comprehension. Educational Research Quarterly, 27, 49-57.

Hausheer, R., Hansen, A. \& Doumas, D. (2011). Improving reading fluency and comprehension among elementary students: Evaluation of a school remedial reading program. Journal of School Counseling, 9, 1-17.

Higgs, J. (1988). Planning learning experiences to promote autonomous learning. In D. Boud, (ed.) Developing Student Autonomy in Learning. Sydney: Kogan Page. 
Hirsch, E. D., Jr. (2003). Reading comprehension requires knowledge-of words and the world: Scientific insights into the fourth-grade slump and the nation's stagnant comprehension scores. American Educator, 27, 10-13.

Holmes, V.L., \& Moulton, M.R. (1997). Dialogue journals as an ESL learning strategy. Journal of Adolescent \& Adult Literacy, 40(8), 616-621.

Jonassen, D.H. (1994). Thinking technology. Educational Technology, 34(4), 34- 37.

Lew, M. D.N. \& Schmidt, H.G. (2011). Self-reflection and academic performance: is there a relationship? Advances in Health Sciences and Education Journal, 16 (4), 529-545.

NokhbehRousta, S.A. \& Ghazi MirSaeed, S.J. (2012). The effect of teaching metacognitive reading strategies on reading self-efficacy of Iranian intermediate EFL students. Journal of Academic and Applied Studies, 2 (11), 10-20.

Nourdad, N. (2015). Responses to mediation for six levels of reading comprehension questions based on Bloom's taxonomy. Iranian EFL Journal, 11(3), 94-112.

Qian, D. D. (2002). Investigating the relationship between vocabulary knowledge and academic reading performance: An assessment perspective. Language Learning, 52, 513-536.

Rezaei, A., Rahimi, M.A., \& Talepasan, S. (2012). Exploring EFL learners reading comprehension problems in reading ESP texts. Sino-US English Teaching, 9(3), 982-987.

Savin-Baden, M. (2000). Problem-based Learning in Higher Education: Untold Stories. Buckingham: SRHE/Open University Press.

Sporer, N., Brunstein, J. C., \& Kieschke, U. (2009). Improving students reading comprehension skills: Effects of strategy instruction and reciprocal teaching. Learning and Instruction, 19, 272-286.

Stephien, W.J., Gallagher, S.A. \& Workman, D. (1998). Problem-based learning for traditional and inter-disciplinary classrooms, in R., Fogarty (ed), Problem Based Learning: A Collection of articles. Illinois, Skylight Professional Development.

Su, C. (2006). Evaluation of reading skills applied in the first-year college English reading course. Proceedings of the Tenth International Symposium on English Teaching. Taipei, Crane, 579-587.

Trites, L. (2001). Journals as self-evaluative, reflective classroom tools with advanced ESL graduate students. In J. Burton \& M. Carroll, (Eds.), Journal writing (pp. 59-70). Alexandria, VA: TESOL Publications, Inc.

Walker, B. (2005). Thinking aloud: struggling readers often require more than a model. The Reading Teacher, 58, 688698.

Wirth, K., \& Aziz, F. (2009). Better Learning through Better Reading and Reflecting. Associated Colleges of the Midwest. Available at http://serc.carleton.edu/acm_teagle/projects/wirth.html

Yeh, I. C. (2006). The effects of reading strategies instruction on junior high-school students reading comprehension Taiwan. Unpublished master`s thesis, National Chengchi University, Taipei. 